\title{
CONCEPTS
}

\section{Use of Human Remains Detection Dogs for Wide Area Search After Wildfire: A New Experience for Texas Task Force 1 Search and Rescue Resources}

\author{
Alexandre F. Migala, DO; Susann E. Brown \\ From the Texas Engineering Extension Service, Texas A\&M University, College Station, TX.
}

\begin{abstract}
In September 2011, wildfires in Bastrop County, TX, were the most destructive in the state's history, consuming more than 34000 acres (13 759 hectares) and more than 1600 homes in the process. The wildfires began by consuming more than 30 homes across 2 miles $(3.2 \mathrm{~km})$ in 17 minutes, raising the fear that local residents may not have had sufficient time to escape the conflagration. Texas Task Force 1 deployed for a new mission, the search and recovery of human remains. Although there have been other larger and more widespread fires in the past, it was the speed at which this fire spread that created the environment requiring such a search. The mission was focused primarily on human detection, searching an area almost 72 square miles $\left(186 \mathrm{~km}^{2}\right.$ ) between September 7 and 11, 2011. To our knowledge, never before have human remains detection dogs been tasked with such an undertaking. Lessons learned from this event will educate all levels of government agencies, emergency medical services, fire departments, law enforcement, utilities, veterinary services, and search and rescue/ recovery activities in the future. The utilization of human remains detection canines integrated with search teams trained in larger scale events is one such area that will benefit from this experience, with a final area searched of 15598 acres (6312 hectares).
\end{abstract}

Key words: human remains detection dogs, cadaver dogs, search and recovery, search and rescue, wide area search

\section{Introduction}

The Texas Task Force 1 Urban Search and Rescue (TX-TF1) has been called on by the Governor of Texas to respond many times since its development to help the people of Texas and the United States at times of need. In September 2011, wildfires in Bastrop County, TX, proved to be a new experience for a number of reasons. Not only did this prove to be the most destructive wildfire in Texas's history, consuming more than 34000 acres (13 759 hectares) and more than 1600 homes in the process, but it began by consuming more than 30 homes across 2 miles $(3.2 \mathrm{~km})$ in 17 minutes. ${ }^{1}$ The fear of local residents not having sufficient time to evacuate themselves from the oncoming conflagration resulted in the deployment of TX-TF1 for a new mission, search and recovery of human remains. Although there have been many other larger and more destructive fires in the past,

Corresponding author: Alexandre F. Migala, DO, 4 Hickory Crossing Lane, Argyle, TX 76226 (e-mail: migalaaf@yahoo.com). particularly the wildfires destroying so much of southern California in 2003, it was the speed at which this fire spread that created the environment requiring such a search. The scope and magnitude of the Bastrop wildfires were beyond any mission focusing primarily on human remains detection by the team, searching in an area involving almost 72 square miles $\left(186 \mathrm{~km}^{2}\right)$ from September 7 to 11, 2011. To our knowledge, never before have human remains detection (HRD) dogs been tasked with such a detailed search for human remains of such a large area of scorched geography, with a final area searched of 15598 acres (6312 hectares). ${ }^{1,2}$

\section{Texas Task Force 1 History}

In response to the domestic terrorist bombing of the Murrah Building in Oklahoma City, OK, in April 1995, Texas Engineering Extension Service of the Texas A\&M University System eventually developed TX-TF1. Texas Task Force 1 became a fully deployable resource for 
the Federal Emergency Management Administration (FEMA) Urban Search and Rescue (US\&R) Program in 1998, which subsequently fell under the auspices of the Department of Homeland Security after its formation, and-along with teams from California, Florida, and Virginia-is among the most active US\&R teams in the United States, with more than 90 deployments since its formation. Texas Task Force 1 teams were deployed to New York City after 9/11, New Orleans after Hurricane Katrina, to New Orleans to assist in evacuation of special-needs patients in preparation for Hurricanes Gustav and Ike, and to many parts of Texas to support local agencies after hurricanes, floods, and tornados and in support of federal agencies after the Shuttle Columbia disaster in 2003. Texas Task Force 1 mobilized and stood ready to deploy to Haiti after the earthquake in January 2010, and was activated as a contingency for Super Bowl XLV. Texas Task Force 1 remains the only fully deployable federal US\&R team in Texas. ${ }^{2}$

Given the particular geographic challenges presented by the sheer magnitude of Texas's landmass, TX-TF1 has developed specialized operations in conducting Wide Area Search (WAS) for victims of such disasters mentioned above. Although there are no strict guidelines differentiating how large a particular area must be to be considered a "wide area," the term was created to explain the various search methods used in various circumstances. Wide Area Search differs from the typical Large Area Search (LAS) operations conducted by fire and emergency medical services (EMS) personnel by the even larger geographic areas involved, as is common when hurricanes make landfall or tornados strike. Large Area Search typically focuses on a relatively confined area such as buildings or neighborhoods, whereas WAS is developed in response to TX-TF1's frequent missions to search larger geographic areas using specially conceived approaches for greater efficiency and effectiveness. The Space Shuttle Columbia disaster was an example of a WAS in which multiple agencies cooperated to recover the shuttle while HRD dogs were used to recover the remains of the astronauts. Incorporating search dogs, both for rescue and human remains, is a fundamental part of the planning and operations for TX-TF1. Search dogs have been used for search and rescue (SAR) and WAS for years, most notably for TX-TF1 after Hurricane Ike in 2008, but a mission exclusively focusing on the use of HRD dogs for WAS had never been implemented.

Working dogs have been used for many years by the military, law enforcement, private corporations, and SAR teams for a myriad of purposes ranging from security work and narcotics and explosives detection to searching for living and deceased humans. ${ }^{3-7}$ In the realm of searching for humans, there are primarily 3 types of canines: live-find, cross-trained, and HRD dogs. Live-find canines are of greatest importance for use in disasters given the stated mission of US\&R teams. Cross-trained canines that identify humans whether alive or deceased are frequently used in wilderness searches, but their use is discouraged in disasters because of the limited resources available. Dedicating resources to search for a find without knowing whether the victim was alive or dead would delay responding to those left alive with potentially detrimental consequences.

The Federal Emergency Management Administration formally recognizes only live-find canines, which are typed by the National Incident Management System (NIMS) as Canine Search and Rescue Team-Disaster/ Structure Collapse Human, Type I HR. This typing provides one handler and dog to perform search in heavy, medium, and light construction, as well as natural and man-made debris fields. ${ }^{8}$ None of the disaster standards list a specific area size requirement for search canines, as it was expected that the teams would be searching collapsed buildings and not large tracts of land. Current FEMA live-find typing suggests 120 - to 160 -acre tasks for Type I or II nonspecific air-scent dogs, and 80 to 120 acres for Type III. The terrain encountered in the search area greatly impacts the effective size of the area searched. An important point here is that the US\&R system was developed to deal with collapsed buildings, but the missions encountered by TX-TF1, and other Task Forces, is more often performing WAS. It must be realized that in the larger area, the dogs are not searching every part of their assigned sectors, but they are still searching the collapsed and damaged structures within that area. So, although it may seem that the current FEMA typing does not capture the scope of practice, it does capture the necessary skill set to perform the critical function of searching collapsed buildings within their search area, which may be many acres. In the case of the Bastrop wildfires, the assigned search area was approximately 100 acres (40.5 hectares) per day working 10 - to 12-hour days.

Search canines were integrated with US\&R teams since the beginning of the SAR Task Forces around 1989. Although not officially recognized by FEMA for US\&R teams, HRD dogs have occasionally been requested for specific situations, most notably the Space Shuttle Columbia disaster. Human remains detection dogs have a proven track record demonstrated by extensive experience and research conducted on the ability of canines in SAR of human remains in various environments and under different circumstances. ${ }^{3,9}$ Canines must undergo extensive training and receive special certification to function as HRD canines. ${ }^{3-6,10}$ Historically, 


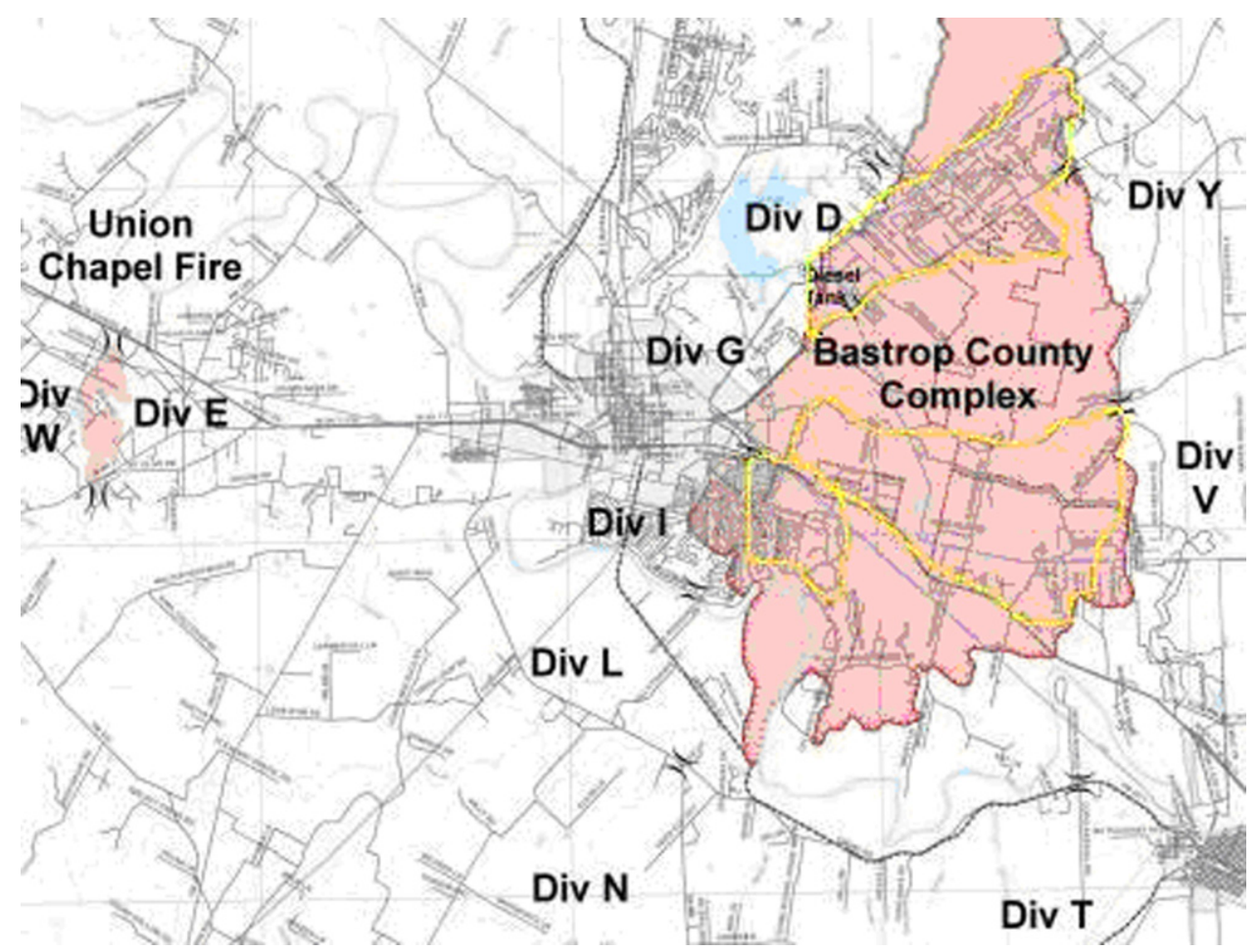

Figure 1. Map of Bastrop wildfire. Areas outlined by yellow lines indicate areas searched by Texas Task Force 1 using human remains search dogs.

because of their specialized purpose, HRD canines are typically called on to search a designated area of particular focus for human remains, such as a building, a crash site, a potential crime scene, or even an archeological site. ${ }^{3,5}$ Because of this focus the size of the area of interest is usually somewhat small and the duration of the search conducted by the HRD canines is of short duration, commonly less than 30 minutes. The National Association for Search and Rescue (NASAR) has defined disaster operations for their training and testing of search dogs as a 30-minute task, which would limit the search area to less than 20 acres depending on the terrain encountered. The NASAR disaster standards are predominantly used by wilderness canine SAR teams and are able to provide search capabilities in light collapse events, and are very effective in that regard.

The pressure for state and local government officials and social concerns to account for missing individuals, and to permit residents to return to what remained of their homes and neighborhoods, resulted in the call for assistance by TX-TF1 and its special skills in WAS and its HRD dogs in the evening of September 6, 2011. Texas Task Force 1 was deployed as a State asset at 0730 hours on September 7, 2011, reporting to the Bastrop County Sheriff's Office to conduct the first of its kind mission for a US\&R team, a purely SAR of human remains in a wildfire (Figure 1). On arrival at Camp Swift shortly after 0900 hours, the Base of Operations $(\mathrm{BoO})$ was established and the initial Area of Operations (AO) was designated. The Forward Operating Base (FOB) was established by 1130 hours, and operations began before 1300 hours. Texas Task Force 1 initially deployed with 4 HRD canines and 60 searchers (a Type I team). For those not familiar with FEMA US\&R teams, a Type III team is a smaller, more rapid 28 -member team. A Type I team is the larger, complete 70 -member team able to perform the full spectrum of SAR including technical and heavy rescue. Also somewhat unique to the FEMA US\&R mission are the use and functions of a $\mathrm{BoO}$ and $\mathrm{FOB}$, which were adopted from military operations in remote areas or those separated from the main force. A BoO is the primary location of command and control for the overall operations where all primary and support functions are located, which incorporated the 2 primary operational locations from ICS (Incident Command System) Base and Camp, whereas the FOB is the "tactical" local command and control for field operations. These terms are commonly used within the US\&R task, which is usually a single resource operating within a larger umbrella organization using the NIMS. After completion of the first day's search operations at 1930 hours, it was determined that additional canine resources 


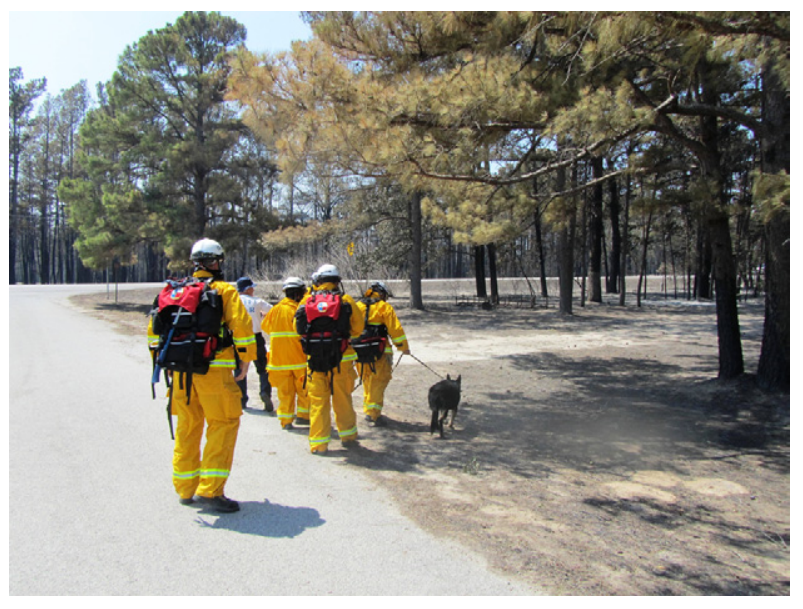

Figure 2. Texas Task Force 1 search team entering search area with human remains canine.

would be required to complete the mission rapidly and effectively. Additional HRD dogs were requested and arrived during the next 2 days, greatly enhancing the ability of the search squads to cover greater territory more effectively. Six HRD canines were ultimately engaged by TX-TF1 in the search (Figure 2). As can be seen from the photo, task force members deployed in fire-retardant PPE (Personal Protection Equipment) with half-face masks because of the persistent heat, fires, and threat of flare-ups, as well as ash that aerosolized readily when the searchers passed.

Adding to the complexity of the search were the additional variables of lack of accountability of residents, the size of the area to be searched, the continued heat and hazards of ongoing fires and hot ash, and the almost complete incineration of many of the areas to be searched. The task of searching such a challenging area imposed demands on the team's HRD dogs not previously encountered, and the dogs were forced to endure search periods exceeding those typically expected for working dogs. The HRD dogs searched 6 to 8 hours per day for repetitive days in temperatures between $90^{\circ}$ and $102^{\circ} \mathrm{F}\left(32^{\circ}-39^{\circ} \mathrm{C}\right)$, low humidity dropping from $35 \%$ in the morning to only $12 \%$ to $15 \%$ in the afternoon, and with only minimal wind. Because of the large search area requiring detailed attention by canines, the dogs were working continuously. Although not measured, ground temperatures in many areas were sufficient to melt the soles of boots. These conditions exposed the dogs to greater risk of dehydration, overheating, and dust and ash inhalation. In addition to frequent rest breaks, additional actions were taken to reduce the strain on the canines, such as transporting them on a large all-terrain vehicle or in air-conditioned vans.
Initially, the approach for "finds" by a canine was to bring another canine to search the same area in an attempt to verify the "find," as the destruction was so extensive as to have potentially destroyed any identifiable remains. This tactic was subsequently identified as too time- and resource-consuming, as well as potentially confusing given the situation in which one canine would identify a "find" and another would not. The operational plans changed to any "find" by an HRD dog was to be considered a positive and not require any further canine verification, and the Medical Team Manager (physician) was called to evaluate the remains.

The Bastrop wildfires disaster was the first time TX-TF1 deployed with an attached organic complete veterinary support team (Figure 3). Support for the canines came in the form of the Veterinary Emergency Team (VET) from the Texas A\&M School of Veterinary Medicine. Texas Task Force 1 supported the VET logistically at the BoO and at the FOB, where the VET was located during each day's mission. The VET consisted of large- and smallanimal attending veterinarians, a veterinary surgeon, a veterinary intensivist, student veterinarians, and veterinary technicians providing care from a mobile surgical clinic housed in a trailer. In addition to supporting TXTF1's HRD dogs, the VET provided emergency care to animals found by TX-TF1 during its search or that were brought to them by animal control officers. Any animal requiring further or additional care was transported, while those not requiring extended care were transferred to animal control officers for the humane shelter.

Federal Emergency Management Administration US\&R does not currently have an identified position for a veterinarian on the US\&R Task Force, although there is a position on the expanded IST (Incident Support Team)

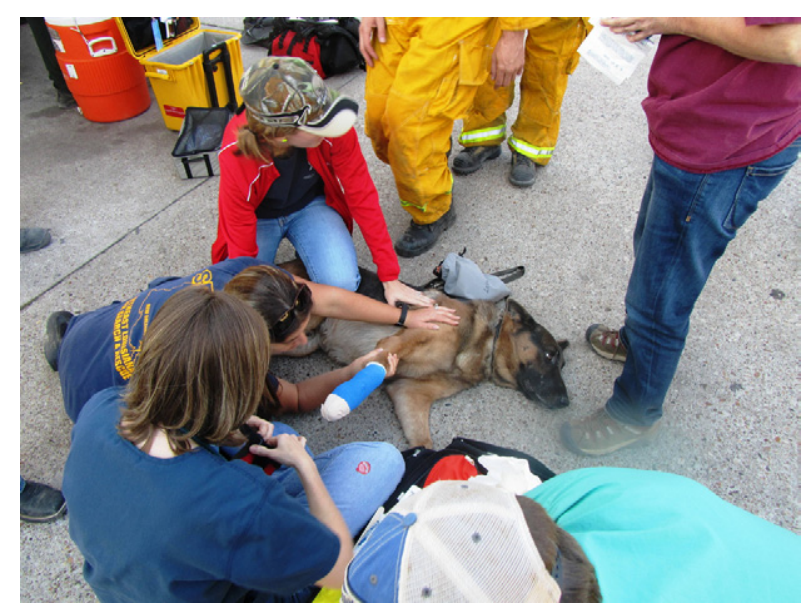

Figure 3. Texas Task Force 1 human remains search dog, Sarge, receiving follow-up care from Texas A\&M veterinarians after sustaining a laceration to the right front paw during search operations. 
for a veterinarian as required by the mission profile. The current practice is to establish contact with local veterinarians willing to assist and trained in treating working dogs when preparing for operations in their geographic area. Several task forces have made arrangements for a veterinarian who is already trained and credentialed in another US\&R position - usually Search Technician - to deploy with them in an ad hoc and informal capacity. Several State US\&R teams have made arrangements to have veterinary support deploy with them. To our knowledge, the Texas A\&M VET is the only full veterinary team to deploy in support of a task force, and only does so for state deployments, not federal declarations.

Of the HRD dogs deployed during the Bastrop wildfires, 3 sustained minor burns to their pads, 1 sustained a laceration to a forepaw web space requiring sutures, and 1 experienced sufficient dehydration and hyperthermia to be withdrawn from performing duties for an afternoon. All dogs received continued monitoring of their health while in the field by TX-TF1 Medical Specialists. Texas Task Force 1 Medical Specialists receive training in veterinary paramedicine in a course developed in a cooperative effort between TX-TF1 and Texas A\&M University School of Veterinary Medicine with training directed specifically to support the mission of the search and HRD dogs of TX-TF1. The HRD dogs received serial evaluations by the VET and task force medics every morning before missions, during the lunch recovery period, and after completion of every day's missions. To reduce the risk of dehydration, each dog received $1000 \mathrm{~mL}$ subcutaneous infusion of normal saline solution before the mission each morning, and received additional infusion of normal saline solution administered subcutaneously or intravenously during the day and after completion of the day's missions as their evaluations warranted. For those not familiar with subcutaneous fluid administration, aliquots of 10 to $20 \mathrm{~mL} / \mathrm{kg}$ can be infused in each spot with care taken to distribute the weight evenly on both sides of the back for balance and comfort. Initially the dogs received fluids subcutaneously, but then all fluids were administered intravenously as it was tolerated better by the dogs. All dogs were provided with protection for their paws after the first day by having their paws wrapped with gauze and tape with or without the use of neoprene and Kevlar booties for additional protection from the heated terrain. Booties have been available for previous missions, but only used occasionally depending on the terrain and environment. The ground temperature all but made the use of booties a requirement for the dogs.

The SAR activities were conducted while authorities were establishing accountability for local residents and determining whether anyone was missing and in what neighborhood they lived, creating an environment of searching each and every residence in neighborhoods and more rural areas until more detailed information directed focused searches. That accountability came from websites, telephonic communications, and reports from friends and neighbors, as well as residents who were traveling across the United States calling and reporting that they were safe. Questions arose when remains resembling human bones were found at a location where there were no known missing people, requiring more thorough investigation by the Travis County Medical Examiner for determination.

\section{Learning Points}

When entering new territory, lessons are always learned as to how to plan for and conduct a mission. The Bastrop wildfires proved to be no exception. The exact extent of the mission was unknown until after our arrival to the $\mathrm{BoO}$ and the first foray into the $\mathrm{AO}$, and a more complete determination and deployment of canine resources ensued. Multiple factors were identified that would affect the effectiveness of the canines during this mission, and included geographic, environmental, and operational factors (see the Table). Although preemptive actions were taken to prevent or mitigate the effect of many of these factors, some were unavoidable. Of greatest importance was the requirement to execute the mission in as rapid and safe a manner as possible, requiring a physical demand placed on the canines not previously experienced (Figure 4). The factor for which the least could be done to either prevent or mitigate was the ubiquitous presence of ash and dry ambient air to which the canines were continuously exposed, enhanced by their closer position to the ground.

The continued preventive medicine approach used in monitoring human activity during TX-TF1 deployments was applied to the HRD canines during this mission, and proved very effective in enhancing the canines' ability to remain operational in a safe manner. The summer heat wave and scorched earth posed significant obstacles to conducting the search while optimizing safety of the

Table. Factors affecting canine endurance

\begin{tabular}{lll}
\hline \multicolumn{1}{c}{ Geographic } & Atmospheric & \multicolumn{1}{c}{ Operational } \\
\hline Uneven terrain & Ambient heat & Operational tempo \\
Hazards (trees/metal) & Humidity & Time limitations \\
Heated ground & Ash/dust & Political considerations \\
& Wind & Social considerations \\
\hline
\end{tabular}




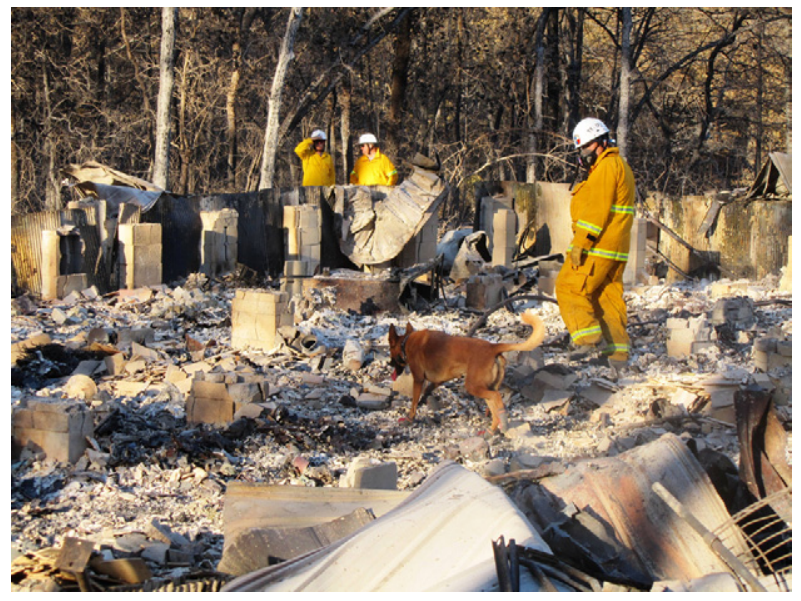

Figure 4. Human remains search dog, Jetta, and her handler, Mary Lehman, conducting search of residential remnants.

canines and humans. Standard practices of continued monitoring of the task force members was emphasized to include several medical assessments during the day by the task force Medical Section and the VET as well as continuously by task force Medical Specialists in the field. Strict adherence to medical and veterinary surveillance likely prevented more serious injuries to the dogs, particularly their paws. The premission and repeated hydration via intravenous catheters was found to be more expeditious and better received by the canine handlers and dogs than using subcutaneous injections given the amount of hydration required in this environment. As this was the first deployment of the VET with TX-TF1, no formal standard operating procedures or field operating guidelines had been established, but are in the process of being developed.

The Bastrop wildfires were the most destructive fires in Texas's history, and were a unique event in wildfires owing to the speed and extent of the conflagration. Government and academic agencies are conducting investigations of the Bastrop wildfires to determine whether either such an event can be prevented or its effects can be mitigated in the future. In addition to the massive firefighting efforts, the scope of the search for human remains on the scale undertaken by TX-TF1 has never before been attempted. Lessons learned from this event may benefit all levels of government agencies, EMS, fire departments, law enforcement, utilities, veterinary services, and SAR activities in future endeavors. The utilization of HRD canines integrated with search teams in larger scale events is one such area that will benefit from this experience.

\section{Acknowledgments}

We would like to express our appreciation to Jeff Saunders, Chief of Operations for TX-TF1, for the support and guidance in the development and preparation of this article; Lori Gibson, DVM, MA-TF1; and Teresa MacPherson, Chair, VA-TF1, FEMA US\&R Canine Sub-Group for their support and comments as well as enthusiasm in the use of canines for SAR.

\section{References}

1. Texas Forest Service. Available at: http://txforestservice. tamu.edu/main/default.aspx. Accessed September 19, 2011.

2. Texas Task Force 1. Available at: http://www. texastaskforce1.org/. Accessed September 19, 2011.

3. Rebmann A. Cadaver dogs: a search tool for locating human remains. Available at: http://barksar.org/ Cadaver_Dogs_A_Search_Tool_for_Locating_Human Remains.pdf. Accessed September 19, 2011.

4. Lowy A, McAlhany P. Human remains detection "cadaver dogs": the latest police canine detector specialty. Available at: http://www.fdiai.org/Newsletter\%20Archives/Newsletters/ April2000/april2000lowy\&mcalhany.pdf. Accessed May 21, 2012.

5. Komar D. The use of cadaver dogs in locating scattered, scavenged human remains: preliminary field test results. $J$ Forensic Sci. 1999;44:405-408.

6. Lasseter AE, Jacobi KP, Farley R, Hensel L. Cadaver dog and handler team capabilities in the recovery of buried human remains in the southeastern United States. J Forensic Sci. 2003;48:617-621.

7. Komar D, Galloway J. Cadaver dog training/research project begins in Alberta. RCMP Gazette. 1998/99;60/61(12/ 1):2-4.

8. National Urban Search and Rescue Response System. Canine Search Specialist Certification Annex to the National US\&R Response System Operations Manual. May 2010. Available at: http://www.disasterdog.org/pdf/policies/evaluationforms2010/CSSC_Annex_May2010.pdf. Accessed May 21, 2012.

9. Hochrein MJ. A bibliography related to crime scene interpretation with emphases in geotaphonomic and forensic archaeological field techniques. Washington, DC: United States Department of Justice, Federal Bureau of Investigation, FBI Print Shop; 2004.

10. American Rescue Dog Association. Human Remains Detection Certification Evaluation. 2008. Available at: http://www.ardainc.org/docs/ARDA_Human_Remains_ Evaluation.pdf. Accessed May 21, 2012. 